\title{
Capital intelectual, gestión del conocimiento y la gestión de recursos humanos
}

\section{Intellectual capital, knowledge management and human resources management}

Ing. Lubiza Osio Havriluk

Universidad de Carabobo, Venezuela

Autor para correspondencia: Lubiza@gmail.com

Fecha de recepción: 09 de Noviembre de 2016 - Fecha de aceptación: 20 de diciembre de 2016.

\section{Resumen}

El tema de capital intelectual y la gestión del conocimiento están permeado por diferentes paradigmas que atribuyen a la gestión de recursos humanos un significado diferenciador, que coincide, según algunos autores con la transición/evolución a la llamada sociedad de la información y todo lo que ésta conlleva. En tal sentido el objetivo medular de este ensayo viene dado por comprender como las Tecnologías de Información han incidido en el desarrollo del capital intelectual y la gestión, tanto del conocimiento como de los recursos humanos en las organizaciones. Para que esto fuese posible la metódica requerida precisó de un nivel descriptivo de apoyo fundamentalmente documental, que permitiera explanar las nociones básicas sobre el tema, entender las características de la sociedad de la información, precisar los conceptos de gestión del conocimiento y el capital intelectual; para luego esbozar las visiones de la empresa del aprendizaje y el aprendizaje permanente, para finalmente dar luces sobre cuál es el papel de la gerencia de recursos humanos en este nuevo contexto organizacional.

Palabras clave: Gestión del Conocimiento; Gestión de Recursos Humanos; Tecnologías de Información

\begin{abstract}
The issue of intellectual capital and knowledge management is permeated by different paradigms attributed to human resource management a differentiator meaning, which coincides, according to some authors with the transition / evolution to the so-called information society and all that it entails. In this regard, the core objective of this test is given by understanding how Information Technologies have influenced the development of intellectual capital and management, both knowledge and human resources in organizations. To make this possible the methodical required said in a fundamentally documentary descriptive level of support, which would allow grading the basic notions on the subject, understand the characteristics of the information society, to clarify the concepts of knowledge management and intellectual capital; then outline the visions of the company's learning and lifelong learning, to finally shed light on what is the role of human resource management in this new organizational context.
\end{abstract}

Key Words: knowledge management; human resource management; Information Technologies 


\section{Introducción}

\section{Situándonos en el contexto}

Para hablar hoy día del Capital Intelectual, Gestión del Conocimiento y la Gestión de Recursos Humanos, es necesario ubicarnos conceptualmente en la sociedad actual. Para ello, hay que explorar la sociedad de la información y la sociedad del conocimiento. Dos sociedades que no parecen estar separada, sino que son una misma sociedad vista desde dos perspectivas distintas, pero en donde convergen dos elemento: el uso de las tecnologías de la información (TI) y el procesamiento de la información.

La sociedad de la información trajo consigo muchos cambios, sobre todo en la forma de concebir las cosas y las personas. Como lo indica Castells (1996: 61), la sociedad de la información es "un acontecimiento histórico al menos tan importante como lo fue la revolución industrial del siglo XVIII, inductor de discontinuidad en la base material de la economía, la sociedad y la cultura". Esta es una sociedad, donde las TI han realizado una gran revolución. Para Castells (1996: 59), esta revolución se caracteriza por "por la transformación de nuestra «cultura material» por obra de un nuevo paradigma tecnológico organizado en torno a las tecnologías de la información”.

Esto significa que la concepción del mundo que se tenía en la sociedad industrial, ha cambiado; no se pueden observar los eventos que ocurren de la misma manera y bajo el mismo paradigma material. Debido a, que la aparición de las TI ha influenciado la forma de hacer las cosas y a las mismas cosas, desplazando algunas, mejorando otras y creando nuevas posibilidades. En el año 2016, hablamos de la Internet de las cosas, de la nanotecnología, el transhumanismo, la singularidad tecnológica, y no podemos pretender que toda esta revolución no nos afecte a todos.

La sociedad del conocimiento, según Castells (2002), se trata de una sociedad en la que las condiciones de generación de conocimiento y procesamiento de información han sido sustancialmente alteradas por una revolución tecnológica centrada sobre el procesamiento de información, la generación del conocimiento y las tecnologías de la información. Esto no quiere decir que la tecnología sea lo que determine; la tecnología siempre se desarrolla en relación con contextos sociales, institucionales, económicos, culturales, etc. (En línea)

Bajo este concepto, se puede entender que la sociedad del conocimiento tiene sus bases en la sociedad de la información, que una está inmersa en la otra. Pareciese, que la sociedad de la información fue evolucionando, ya que no hay información sin conocimiento; así fue necesario empezar a generar nuevo conocimiento para generar nueva información. Castells (2002: en línea) apunta que "al hablar de sociedad del conocimiento —en otros casos, sociedad de la información, etc. - nos estamos refiriendo a la constitución de este nuevo paradigma tecnológico". Claro está todo esto dentro del contexto impulsado por las Tecnologías de la Información.

Rifking (2000), a estas sociedades la denomina la era del acceso, sobre ella indica: 
En esta nueva era, los mercados van dejando sitio a las redes y el acceso sustituye cada vez más a la propiedad. Las empresas y los consumidores comienzan a abandonar la realidad básica de la vida económica moderna: el intercambio mercantil de la propiedad entre compradores y vendedores. Esto no significa que la propiedad desaparezca en la venidera era del acceso. Antes al contrario... Los mercados se mantienen pero tienen un papel cada vez menor en los asuntos humanos... (p. 14).

Esta era plantea una sociedad en donde los intangibles adquieren mayor valor, los mercados se transforman y surge una nueva economía basada en lo intelectual, la tecnología y las redes. Cada vez la propiedad inmaterial va teniendo mayor importancia y valor. Como lo sugiere Rifking (2000),

En la economía-red, en lugar de intercambiar la propiedad, es más probable que las empresas accedan a la propiedad física y a la intelectual. Por el contrario, la propiedad del capital físico, que en su momento fue el núcleo del modo de vida industrial, se convierte cada vez en algo más marginal con respecto al proceso económico. Es más probable que las compañías lo consideren como un simple gasto operativo en vez de considerarlo una inversión y, en algunos casos, lo toman prestado en lugar de apropiárselo. Por otra parte, el capital intelectual es la fuerza motriz de la nueva era y lo más codiciado. Los conceptos, las ideas, las imágenes — no las cosas - son los auténticos artículos con valor en la nueva economía. La riqueza ya no reside en el capital físico sino en la imaginación y la creatividad humana. Deberíamos señalar que el capital intelectual rara vez se intercambia. Por el contrario, los proveedores lo retienen rigurosamente y lo arriendan u ofrecen a otros la licencia de uso por un tiempo delimitado. (Pp.14-15)

Así, el contexto en donde se desarrollan los puntos a abarcar en este artículo, es una sociedad donde las TI han dado origen a todo el nuevo mundo digital que conocemos, un nuevo lenguaje digital en donde la información se crea, se transmite, se comparte y se recobra. Un mundo netamente lleno de unos y ceros, que navegan en el ciberespacio y las redes, donde las personas pierden identidades y las cosas empiezan a ganarlas. Así, con la aparición de la Internet muchos campos se han abierto para las personas, las relaciones personales, las empresas, la cultura, entre otros.

Esta es una sociedad donde existe una estrecha relación entre la cultura -creación y manipulación de símbolos- y las fuerzas productivas (Castells, 1996). Donde el conocimiento tiene un valor esencial, donde producir conocimiento es lo que genera valor, "por primera vez en la historia, la mente humana es una fuerza productiva directa, no sólo un elemento decisivo en el sistema de producción" (Castells, 1996: 62). Como lo diría Taspcott (1998), es la era de la inteligencia interconectada y el ingenio humano.

\section{El Capital Intelectual y la Gestión del Conocimiento}

Como lo apuntan Rifking (2000), Castells (1996) y Taspcott (1998), el conocimiento se hace cada vez más imprescindible para la sociedad. Para finales de la década de los $90 \mathrm{y}$ principios de los 2000, las empresas empezaron a preocuparse por estos temas y a darle valor al conocimiento que cada persona tenia y producía dentro de ella. Ya que sabían que estos eran los 
que permitían aumentar la productividad de las organizaciones, a esto se le denominó Capital Intelectual. Stewart (1998:9), lo definió como "la suma de todos los conocimientos que poseen los empleados de una empresa y le dan a éstas una ventajas competitiva".

"El capital intelectual es material intelectual - conocimientos, información, propiedad intelectual, experiencia - que se puede aprovechar para crear riqueza" (Stewart, 1998:10). En este sentido, todo aquello que se produce con la mente se transforma en fuerza productiva, que permite a las organizaciones alcanzar nuevos mercados o posicionarse mejor en los que ya participa, además permite crear un mejor clima organizacional y una forma de trabajo orientada a la producción del conocimiento.

Se debe entender, que en el siglo XXI, están quedando obsoletas las matrices tecnológicas predominantes y esto tiene considerables efectos en los mercados y en las estructuras organizacionales. Las TI han revolucionado a las organizaciones y han generado nuevas formas de trabajo que requieren de gente más especializada y de mayor conocimiento. El know-how se ha convertido en un factor totalmente estratégico del proceso de producción, y una de las inversiones más rentables de toda la economía. En esta nueva sociedad, el capital debe enfocarse hacia la productividad de los trabajadores del conocimiento y de los servicios, lo cual constituye verdaderos desafíos para los diferentes sectores.

Esta es la sociedad de la incertidumbre, la "sociedad del riesgo global" (Beck 2002). Estamos ante grandes desafíos que generan situaciones de extrema complejidad para el desempeño organizacional, aunado a esto están factores como: la flexibilidad laboral, la inestabilidad, las nuevas formas de trabajo, entre otros. Haciendo todo esto que captar la realidad en su totalidad sea difícil de lograr, y por ende las organizaciones se hacen más complejas. Esto hace necesario que las organizaciones deban trascender sus prácticas y herramientas tradicionales; es el momento de gestionar inteligentemente la información y el conocimiento.

Ahora, ¿Qué deben hacer con su capital intelectual las organizaciones? Las organizaciones deben construir sistemas, que permitan no sólo almacenar el conocimiento, sino recuperarlo, trasmitirlo y crearlo. También deben crear estrategias para incentivar su producción y uso, así como crear programas de capacitación y adiestramiento que permitan constantemente preparar al personal para los nuevos retos que afrontan. Un sistema de incentivos basado en la producción del conocimiento también ayuda a que el personal se entusiasme a pertenecer a esta nueva cultura organizacional.

Para hacer todo esto posible, es necesaria la gestión del conocimiento, la cual se conoce como "el proceso de gerenciar continuamente el conocimiento de todo tipo para satisfacer necesidades presentes y futuras, para identificar y explotar recursos de conocimiento tanto existentes como adquiridos para desarrollar nuevas oportunidades" (Quintas, Lefere y Jones, 1997: 387). La gestión del conocimiento es la combinación de sinergias entre datos, información, sistemas de información y la capacidad creativa e innovadora de los seres humanos.

Se debe entender que la gestión del conocimiento tiene dos componentes: a) el concerniente a la gestión, el cual involucra las funciones de planificación, organización, dirección y control de procesos para la consecución de los objetivos propuestos, según la misión y visión de éstas; y por otra parte, b) la capacidad y el talento de los individuos y organizaciones 
de transformar información en conocimiento, generando creatividad y poder de innovación, lo que incentiva la toma de decisiones y dinamiza las organizaciones.

La gestión de conocimiento, es la unión entre la dirección y los individuos para generar un banco de información que le permita a la organización capitalizar todo su conocimiento y disponerlo de manera efectiva para la operatividad de la organización.

\section{La empresa del aprendizaje y el aprendizaje permanente}

Capacitarse, estudiar, formarse, son las vías para lograr el desarrollo en esta nueva sociedad, el empleado debe comprender que en la organización actual, si no está en constante desarrollo no tiene cabida. En la actualidad existen dos tendencias de formación organizativa: la empresa del aprendizaje y el aprendizaje permanente.

En la primera, la organización se ve a sí misma como un mecanismo de formación y educación de sus empleados, mientras que en la segunda se ve a sí misma como el cliente de la unidad indivisible que forma cada empleado y su pericia -el individuo es quien tiene la responsabilidad de mantenerse a sí mismo como un activo deseable-. Ambos enfoques tienen aspectos positivos, pero sólo darán resultado si se comprenden los objetivos estratégicos de la compañía. Si los empleados se consideran como un activo corporativo, la formación será, entonces, su mantenimiento. Los programas de reciclaje profesional, que se traducen en una mayor eficacia, también son activos, de manera que la formación corporativa es una de las vías principales a través de las cuales se formará a los empleados de la empresa del tercer milenio (Brooking, 1997: 6).

Estas dos visiones, plantean dos formas antagónicas de ver la formación. En una la organización es un espacio para formar al personal que en ella labora, y esta es una actividad que a ella le incumbe. La otra, se basa en que las organizaciones requieren de gente formada y la misma gente debe hacer los esfuerzos de formación. ¿Cuál de estas tendencias tiene más pertinencia en las organizaciones de nuestra realidad? En estos momentos, tanto las empresas como las personas están conscientes de la importancia que tiene a formación en el mundo empresarial.

En la mayoría de los países en vía de desarrollo, se da más el aprendizaje permanente, ya que son pocas las empresas que tienen cultura del aprendizaje. Esto se da en grandes empresas quienes han comprendido el valor del aprendizaje- o en las trasnacionales que tienen ese valor heredado. Es más difícil que las pequeñas y medianas empresas tengan esta cultura, por su misma dinámica y estructura. Lo ideal, sería una combinación de ambas visiones, en donde la empresa tenga esa cultura del aprendizaje, lo fomente y apoye al personal a lograrlo; y que las personas también tengan en sus hábitos la formación fuera de la organización, como un proceso de mejora personal.

\section{A modo de reflexión}

La Gestión del Conocimiento y la Gestión de Recursos Humanos (GRRHH) tienen como punto convergente, el desarrollo de conocimientos y habilidades por parte de los trabajadores. 
Por ello, la GRRHH, debe: a) desarrollar planes de carrera que permitan a los trabajadores formarse y crecer dentro de la organización; b) desarrollar sistemas de medición de competencias y desempeño para lograr a través del aprendizaje eliminar las brechas existentes, c) implementar mejores sistemas de reclutamiento y selección que permitan escoger el personal adecuado y alineado con la cultura del aprendizaje permanente y con disposición a la formación; d) crear sistemas de incentivos, tanto monetarios como no monetarios, que permitan estimular el aprendizaje en la organización y las personas. Es importante entender que la GRRHH, en esta sociedad de la información, tiene un rol protagónico y esencial dentro de las empresas con cultura de aprendizaje. Ya que el personal que maneja esta gestión dentro de las organizaciones, son las manejan y son responsables del capital intelectual, no solo de la institución sino del país en el que operan y al que pertenecen.

\section{Bibliografía}

Beck, U. (2002). La sociedad del riesgo global. Siglo Veintiuno de España editores, s.a.: Madrid.

Brooking, A. (1997). El capital intelectual. El principal activo de las empresas del tercer milenio.

Paidós: Barcelona, España.

Castells, M. (2002). La dimensión cultural de Internet. En: Cultura y sociedad del Conocimiento: Presente y perspectivas de futuro. Universidad Abierta de Cataluña. Disponible en: http://www.uoc.edu/culturaxxi/esp/articles/castells0502/castells0502.html

Castells, M. (1996). La era de la información: economía, Sociedad y Cultura. Volumen 1. La Sociedad Red. Madrid: Alianza Editorial.

Quintas, P, Lefere, P. y Jones, G. (1997). Knowledge Management: a Strategy Agenda. En: Journal of long Range Planning. Vol 30. Iss3.

Rifking, J. (2000). La era del acceso. La revolución de la nueva economía. Paidós.

Stewart, T. (1998). La nueva riqueza de las organizaciones: el capital intelectual. Ediciones Granica S.A.: Buenos Aires.

Taspcott, D. (1998). Creciendo en un entorno digital: La generación Net. Mc. Graw Hill 